and particularly to Dr. MacMunn, of Wolverhampton, the recognized expert in the spectroscopy of anima pigments.

TRANSFERRING WASH SOLUTIONS. The tube, $a, b$, is kept full and gently overwater supply, the excess being conducted to a sink
through the pipe, $c, d$. When the cock, $e$, is opened the tube, $a, b$, tends to empty itself into the large bot-
tle, $\mathrm{F}$, which at the start is full of air. The air in $\mathrm{F}$ is tle, $\mathbf{F}$, which at the start is full of air. The air in $\mathbf{F}$ is

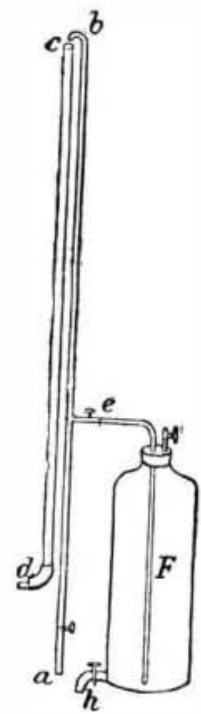

pressed air is conducted by $1 / 4$ inch lead piping to various convenient parts of the laboratory, where any may be attached by its short tube, and the wash water thors the bottle used is one large enough to suffic or half a day's continu is allowed to drain into the sink by opening the

\section{A WASH FUNNEL FOR OXIDIZABLE PRECIPITATES.} By J. A. Forret.

THE funnel, A, is fitted with a perforated metal cone, and covered with a circular piece of wood carrying India rubber tubes furnished with spring clips. The wor.den cover has also a glazed aperture as large as
the diameter of the funnel will admit, to enable the the diameter of the funnel will admit, to enable the stem of A is fitted a piece of India rubber tubing, $\mathbf{F}$, serted ; underneath is placed a beaker or basin of convenient size containing water, under the surface of
which the glass tube dips. Into the tube, $D$, the stem

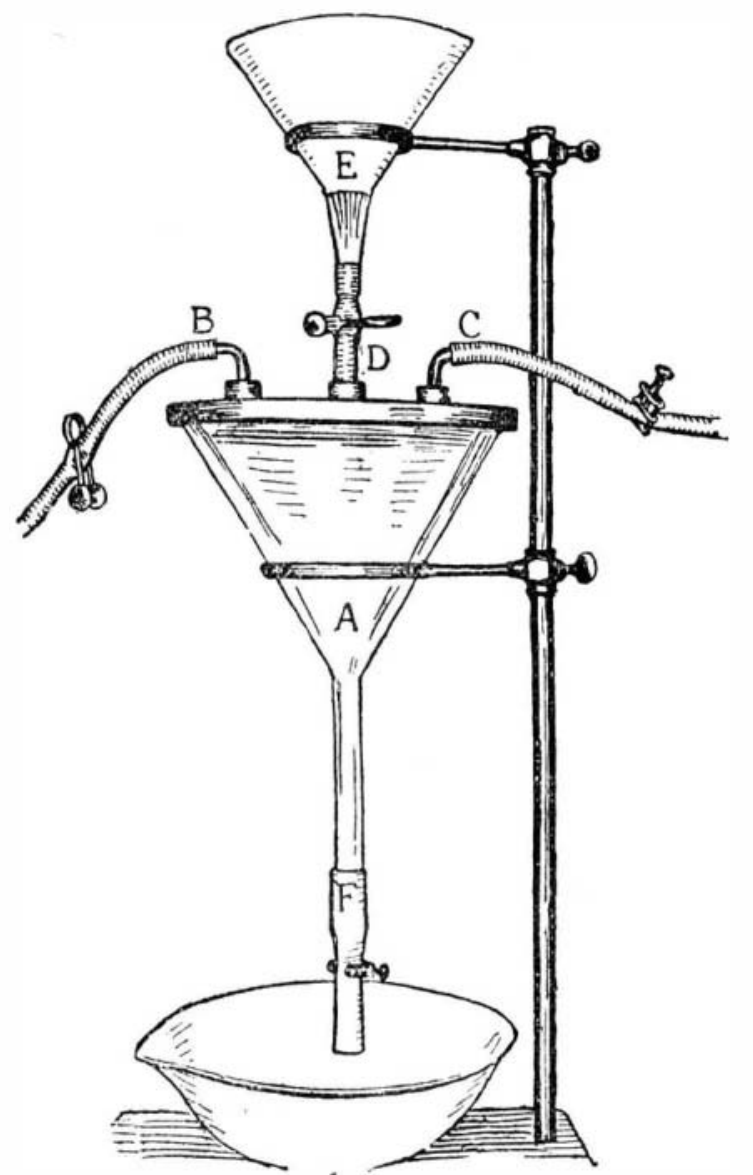

of a second funnel, $E$, is inserted : both funnels are conveniently supported in the rings of a retort stand.
The apparatus is used in the following manner: A The apparatus is used in the following manner: A
piece of fine calico is placed inside the metal cone, and the wooden top cemented to the funnel, $A$, by means of almond meal made into a stiff lute with water to which a little glycerine has been added. The tube, D, is closed, and a current of coal gas, carbonic anhydride olp other suitable gas is passed through the funnel by
the tubes, B and $\mathrm{C}$, to displace atmospherie air. The precipitate to be treated is poured into the funnel, $E$, and by means of the elip at D rapidy transferred to
the funnel, A. When the bulk of the water has passed through the funnel, the tube, $F$, is closed by a the funnel, E. After the lapse of a few minutes the precipitate is practically free from soluble salt. tube, $\mathrm{C}$, is now closed and the precipitate allowed to It is It is desirable to maintain a gentle current of gas while the washing is being carried through ; and when against the entrance of atmospheric air through any aw in the connections.

Ferrous carbonate is the only salt I have had oceasion to treat in this way, the wash bottle referred to being used to precipitate the carbonate. With some
slight modification of the funnel, A, however, I believe slight modification of the funnel, A, however, I believe both for precipitating and washing such unstable salts as ferrous carbonate, ferrous phosphate, etc.-Chem. and Drug.

Just Published,

THE MANUFACTURE OF LIQUORS AND PRESERVES.

By J. De Brevans.

PRICE \$3.00,

Postraid.

The author is an eminent French chemist who has devoted much time and study to the preparation of consists in the formulas, which number over 300 , and are so arranged that, if the manufacturer has no distilling plant of his own, he can yet make many of the liquors from the essences. The manufacturer of French liqueurs, etc., from essences is very profitabie and does not requirelarge capital. Thera w materials, the plant of the distiller, etc., are described according to the best modern practice. The book has 65 illust
tables, and a full index. Send for Table of Contents.
MUNN \& Co., Publishers 36.1 Broad way, New York.

Now READY.

Fourteenth Edition of EXPERIMENTAL SCIENCE. REVISED AND ENLARGED.

120 Pages and 110 Superb Cuts added.

The unprecedented sale of this work shows conclusively that it is the book of the age for teachers, students, experimenters, and all others who desire a ge In the new matter contained in the last edition will together with other new and interesting Optical Illusions, the Optical Projection of Opaque Objects, new oints in Photography, including Hand Cameras, Cane Cameras, etc.; Systems of Electrical Distribution, lectrical Ore Finder, Electrical Rocker, Electric Chimes, How to Color Lantern Slides, Study of the
Stars, and a great deal of other new matter which will prove of interest to scientific readers.

840 pages, 782 fine cuts, substantially and beautifully bound. Price in eloth, by mail, \$4. Half moroceo, \$5. Send for illustrated circular. MUNN \& Co., Publishers,
OFFICE or THE SCIENIFI A A MRIICAN.
361 Broadway, New York. STAR † MAPS.

Bx Richard A. Proctor, F.R.A.S.

A series of twelve elegantly printed Maps of the prepared for use in North America. With deseriptions accompanying each map, giving the names of th cipal stars and constellations, showing their relative positions at given hours and days of the month.

A mecially general knowledge of the starry realms To which is added a description of the method of preparing and using artificial luminous stars as an aid ous stars and constellations, by Alfred E. Beach. Altogether this is one of the most popular,
and valuable works of the kind ever published. and valuable works of the kind ever published. \$2.50, postpaid. MUNN \& Co., Publishers, THE SCIENTIFIC AMERICAN CYCLOPEIIA OF RECEIPTS, NOTES AND QUERIES. 708 Pagtes. Price \$5.00.

Bound in Sheep, $\$ 6.00$. Half Moroceo, $\$ 6.50$.

This splendid work contains a careful compilation Notes and uneries of correspondents as published in the SCIENTIFIC AMERICAN during nearly half a century past; together with many valuable and import

Over Twelve Thousand selected receipts are
here collected; nearly every branch of the useful arts being represented. It is by far the most comprehensive volume of the kind ever placed before the public
The work may be regarded as the product of the The work may be regarded as the product of the
studies and practical experience of the ablest chemist and workers in all parts of the world; the informatio ensed in concise form, convenient for ready use. Almost every inquiry that can be thought of relat An to formuly used in the various manufacturing
dustries, will here be found answered. Instructions for working many different processes in
Ins arts are given. How to make and prepare many Those who are engaged in any branch of industry robably will find in this book much that is of praccal value in their respective callings.

Those who are in search of independent business or mployment, relating to the manufacture and sale of useful articles, will find in it hundreds of most" excel-
lent suggestions. MUNN \& Co., Publishers,
TI $\mathbf{F}$

\section{Scientific American Supplement.} PUBLISHED WEEKLY.

Terms of Subscription, $\$ 5$ a Year.

Sent by mail, postage prepaid, to subscribers in any art of the United States or Canada. Six dollars a Ant prepaid to any foreign country.

All the back numbers of The Supplement, from the commencement, January 1, 1876, can be had. Price, 0 cents each.

All the back volumes of The Supplement can likewise be supplied. Two volumes are issued yearly. Price of each volume, $\$ 2.50$ stitched in paper, or $\$ 3.50$ bound in stiff covers.

Combined Rates.-One copy of Scientific AMeriCAN and one copy of SCIENTIFIC AMERICAN SUPPLEMENT, one year, postpaid, $\$ 7.00$

A liberal discount to booksellers, news agents, and MUNN \& CO., Publishers, 61 Broadway, New York, N. Y.

TABLE OF CONTENTS.

ARCHAOLLOG F.-A Buried Roman City Revealed byt he Grow-
ine Corn.-A curious and interesting discovery in England of the The Museum of Nuremberg.-An interion court in the famoü 1479

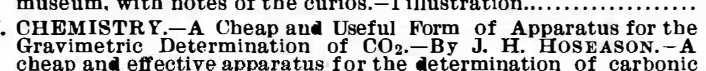

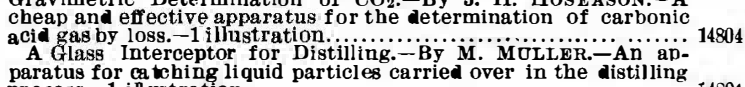

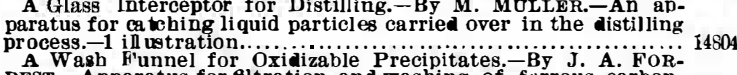

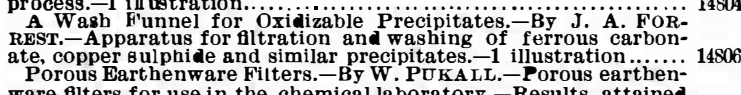

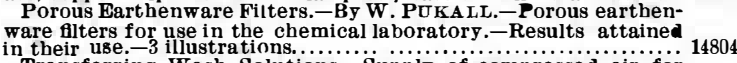

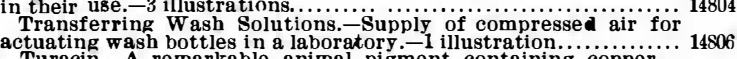

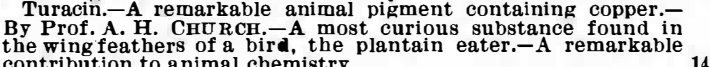
COLUM BIAN EXPOSITION.-Germany at the World's Colum-
bian Exposition.-A most interesting account of the German ex-

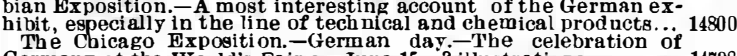

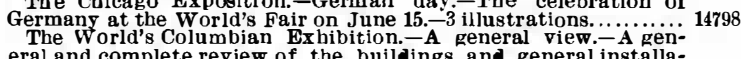
eral and complete review of the building and general installa-
tions at Chicaco.-First installanent.-1 illustration.................. 14795

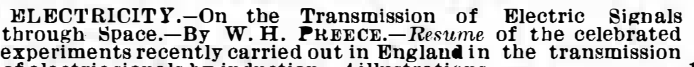
The Electric Match.-An electric cigar lighting apparatus, with
14802

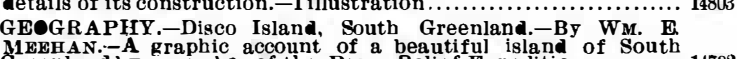

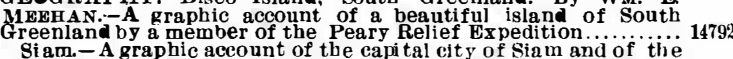

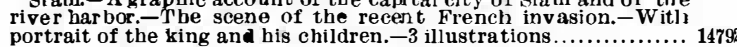
T. HXGIENE.--The Action of Cold and Warmth on Muscular Fa-
tipue.-Recent experiments on the physiology of man.-Results

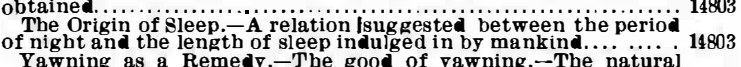

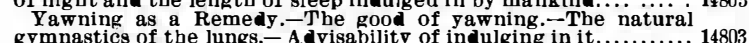
II. MATHEMATICS.-Simplifed Multiplication. - Practical and
simple wettod of performing the operation of multiplication.... 14803

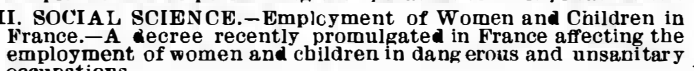

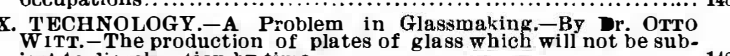

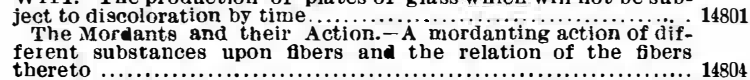
New Catalogule of Vallahble Papers" Contained in Scientific American Supplement during the past ten years, sent free of charge to any
address. MUNN \& CO., 361 Broad way, New York. Useful Engineering Books Manufacturers, Agriculturists, Chemists, Engineers,
Mechanics, Builders, men of leisure, and professional Mechanics, Builders, men of leisure, and professional men, of all classes, need good books in the line of their
respective callings. Our post office department permits small cost. A comprehensive catalogue of useful books by different authors, on more than fifty different subjects, has recently been published, for free circulation, ames of authors. Persons desiring a copy have only at for it, and it will be mailed to them hatdras MUNN \& CO., 361 Broadway, New York. GATENTS!

C6 MESSRS. MUNN \& CO. in connection with the pubIn this line of butsine ese they have had forty-five years' experience, and
now have unequaled facilities for the preparation of Patent Drawings,
Specifications, and the prosecution of Applications for Patents in the Specifications, and the prosecution of Applications for Patents in the
United States, Canada, and Foreign Countries. Mesere. Mnnn \& Co. also
Untend to the preparation of Caveats, Copyrights for Books, Labels.

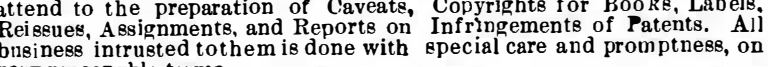
very reasonable terms.
A pamphlet rent free of charge, on application, containing pull infor-
mation about Patents and how to procure them; directions concerning

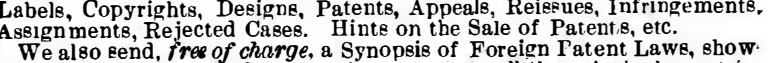
ing the cost and method of securing patents in all the principal countries MUNN \& co., Solicitors or Patente, 361 Broadway, New York.

BRANCH OFFICES.--No. 622 and 624 F Street, Paciflc Building.
near 7th Street, Wabhington, D. C. 